\title{
VERBAL MODIFICATION VIA VISUAL DISPLAY
}

\section{by Edmun B. Richmond and La Donna Wallace - Childers}

\begin{abstract}
The inability of foreign language students to produce acceptable approximations of new vowel sounds by the usual mimicry of teacher and language laboratory tape models initiated a study to devise a real-time visual display system whereby the students could match his vowel production to a visual pedagogical model and effectively shape his own approximations of the target vowel. This study utilized readily available amateur radio equipment and a standard oscilloscope as the visual display device. The system was tested under experimental conditions utilizing university students enrolled in first-year German. Resultant statistical data gave support to the visual system as being superior in aiding the acquisition of four vowel sounds, as opposed to the usual language laboratory method used in most of today's foreign language classes.
\end{abstract}

The shaping of appropriate phonological behavior in the foreign language class has long bcen relegated to student identification and subsequent mimicry of a correct pronunciation model produced by the classroom teacher or a language laboratory tape recording. This procedure has not always produced the desired results i.e., the production of speech sounds of a foreign language that will be considered acceptable by a native speaker of that language. Travers $(1967$, p. 62$)$ alludes to this as a typical example of behavioral shaping used in foreign language study. However, Valette $(1967$, p. 87$)$ indicates that "learning to identify the phonemes of a new language does not of itsclf imply the ability to produce those sounds." Van Teslaar $(1965$, p. 83) further points out that "there is no guarantee that (the student) will be attending to and preceiving the sound system in the way we want him to." Carroll (1974, p. 142) maintains that teachers "should help the learner form the motor templates that are the basis of phonological skills."

These statements contain sound pedagogical thinking. In actual classroom usage, however, we have not progressed out of the auditory mimicry stage of phonological acquisition. That is, the student is still relying on his ability to auditorily discriminate between a correct and incorrect utterance, and is still dependent upon an outside stimulus (from the teacher or tape) to which he must key his response. He is further dependent on the teacher's approval or disapproval of his responses. Travers (p. 198) states that motor performance tasks "can be improved if the person is given supplementary feedback concerning the size of his errors," while Mueller $(1971$, p. 149) writes that "self-correcting occurs when the student has the opportunity to see and hear the correct model for each of his responses."

In connection with these last two criteria, the authors have developed a visual display device which produces a real-time visual representation of the student's production of a vowel sound at the same time he utters that sound. A model of the correct pronunciation is presented to the student on the face of a cathode ray tube (CRT) which allows him to 
effectively shape his own production of the target sound. In this way, the student can see and hear his production of the vowel, is provided with immediate positive or negative reinforcement, and is provided with feedback regarding the size of his errors.

The visual display device as used in this study consisted of a commercially-built amateur radio Single-Sideband (SSB) transmitter and receiver coupled to a standard oscilloscope. This eliminated the necessity of designing specialized equipment, and the inherent costs in such designs. The Single-Sideband transmission system was chosen because the sinusoidal waveforms generated by an SSB transmitter provide an efficient and pedagogically useful display with which to shape the production of vowel sounds.

Each vowel produces a waveform distinct and different from other vowel waveforms. The sinusoidal waveform itself possesses too much irrclevant information to be useful as the pedagogical model. Instead, the envelope of the waveform is utilized as the model. (See Figures 1 and 2) The envelope shows the relationship of the peaks and valleys of the sinusoidal waveform. It is to this envelope that the student attends. He sees only the relevant information contained in the envelope, i.e., the external shape of the wave. The envelope is presented to the student as a transparent overlay, made from material similar to that used with overhead projectors. As he produces the vowel sound, the sinewave of his vowel production is displayed on the screen of the oscilloscope CRT. He places the envelope overlay on the face of the CRT and attempts to match his production of the vowel by causing the peaks and valleys of his utterance to fall within the range of the envelope. If he produces the sound correctly, the relationship of peaks-to-valleys will be identical with those of the transparency envelope model. If he articulates the sound incorrectly, the peaks and valleys will fall outside of the range of the envelope. In order to modify his articulation of the sound, he changes the shape of his vocal tract (i.e., tongue height, protrusion of lips, etc.) thereby shaping the waveform to conform to the pedagogical model. Michaels (1974, pp. 166-167) cites this an an important process: "The learner himself is in control of the presentation of the stimulus materials, the decision to advance or review, etc., and, by his reactions to his own behavior, providing any relevant consequation."

\section{Equipment Configuration}

For this study, a Heathkit HW-100 transmitter, a Collins 75A4 receiver, and a Tektronix 3A72 oscilloscope were utilized. (See Figure 3) However, any transmitter capable of Single-Sideband transmission, any receiver capable of receiving these transmissions, and any standard oscilloscope can be used. These units can be borrowed from a campus amateur radio club, electronics, or physics department. The equipment requires no permanent 


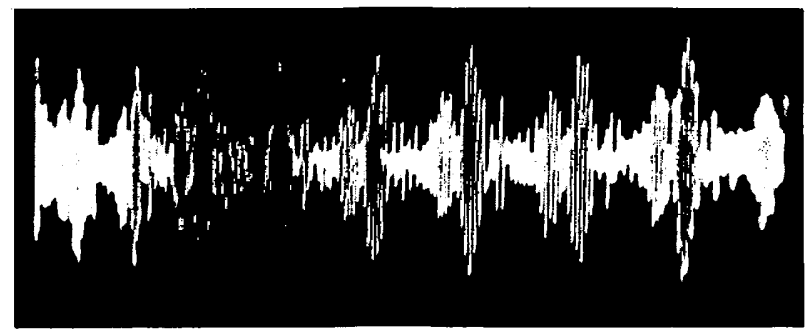

German high front-rounded vowel $/ y /$

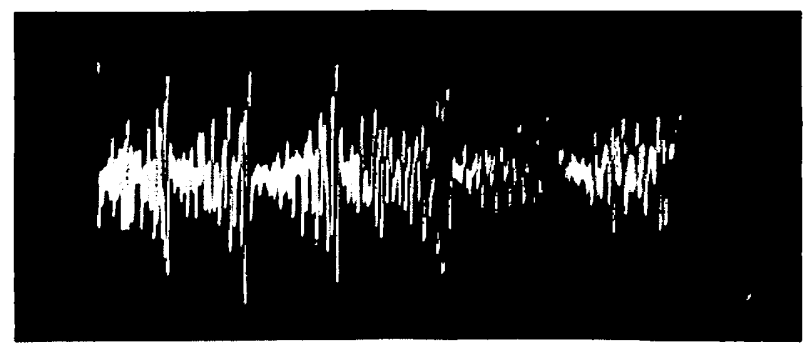

German mid front-rounded vowel /o/

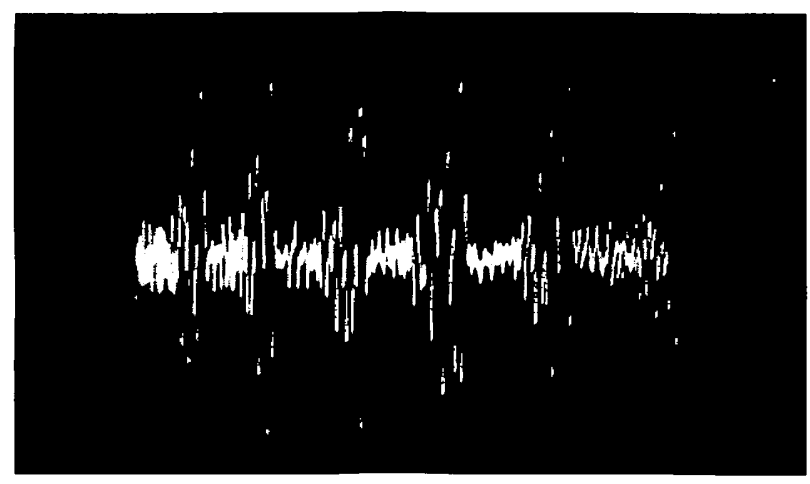

American low front vowel /ae/

Figure 1. Oscilloscope photographs of three vowel sounds generated by the visual display device. 


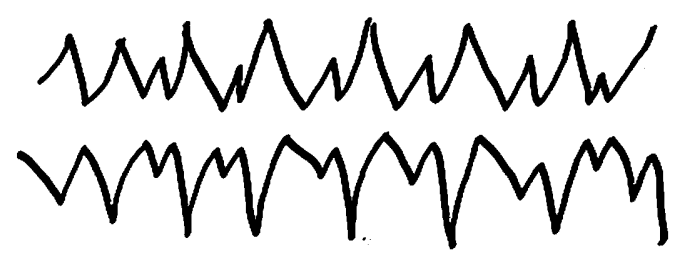

German high front-rounded vowel $/ y /$

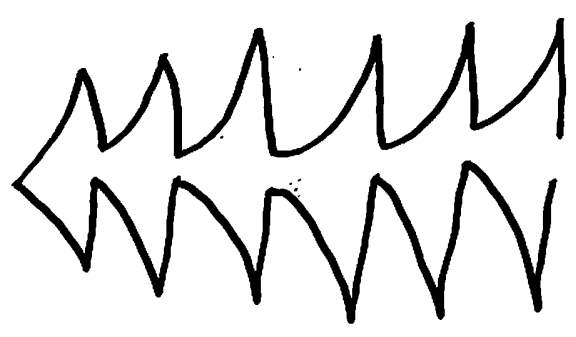

German mid front-rounded vowel /o/
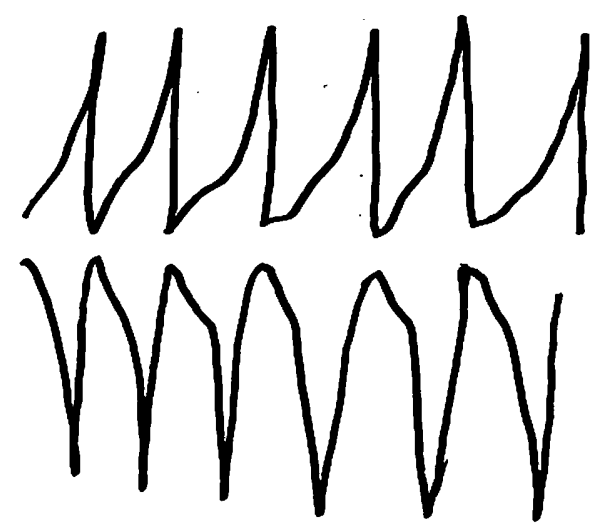

American low front vowel /ae/

Figure 2. Wave cnvelopes of the vowels shown in Figure 1. 
modification, which renders the units totally adaptable to foreign language classes without distroying their originally intended uses in the electronics curriculum. Figure 4 demonstrates the coupling procedures of the three units, while Figure 5 shows a photograph of the wave envelope and wave pattern trace taken directly from the face of the oscilloscope CRT.

The final amplifier tubes of the transmitter are removed from the circuit, since only a minimal amount of radio-frequency energy is needed for transfer to the receiver. The oscilloscope is coupled to the receiver either through the speaker terminals or the headphone jack. Both the transmitter and receiver are tuned to the same frequency. A vowel sound is uttered into the microphone, and its wave pattern is produced on the oscilloscope screen. The receiver tuning control is then varied to bring the wave pattern into the bandpass of the receiver, and to compress the waveform into the optimum pattern from which the overlay transparency is produced. A Polaroid oscilloscope camera is then placed over the CRT screen, and pictures of the waveform are taken as the sounds are produced by the teacher or native speaker. A piece of transparency material is cut to fit the inside demensions of the CRT face. This material is then placed over the Polaroid photograph. The peaks of each wave are connected with a grease pencil to form the envelope pattern. The transparency is placed on the CRT face. The student then attempts to produce a waveform that will fit the confines of the transparency.

\section{Experimental Evaluation}

A pilot study followed by true experimental conditions utilized the visual display device as described herein. The randomized Control-Group Posttest Only research design described by Campbell and Stanley (1963, p. 25) was used. Subjects were university students enrolled in first year German. All subjects had no previous experience with the language. Target sounds were four front-rounded vowels not found in English, i.e., $l y, u, l, o e /$. See Figure 6 for an overview of the experimental task. The experimental group utilized the visual display device, the control group utilized the language laboratory technique commonly used in today's foreign language programs. Both groups practised the same sounds in isolation and the same sounds in actual words. After a two-week experimental treatment, the subjects' utterances of the four vowels in real German words were recorded on magnetic tape, and were evaluated by a panel of impartial teachers of German. They judged that those subjects who acquired the four vowels with the aid of the visual display device demonstrated a statistically superior production than those subjects who utilized the language laboratory system.

Analyses of variance were executed by an IBM 360/65 electronic data processing system. Rater reliability was first determined by using the Intraclass Correlation Formula. A two-tailed t-test tested the significance 
at the .01 level, the mean difference in vowel production adequacy of the control and experimental groups. Those subjects using the visual display device demonstrated a statistically superior level of performance at the .001 level, based upon the ratings. The reliability of the raters was .90 or higher for the four sounds. Table 1 indicates the reliability of the raters, while Table 2 gives the basic statistics and t-test results.

\section{Limitations of the Study}

Vowel production was limited to isolated vowels and vowels within actual German words. Practice in larger utterances. i.e., phrases or sentences, was not attempted. No statement of success other than sounds-inisolation and sounds-in-words can be projected. Further, there is no guarantee that the acquired pronunciation of the target sounds would carry over into classroom oral drills or conversations. The result of the experiment must be viewed only in these terms.

Further Uses of the Visual Display Device

Although the device was used with subjects learning to speak a foreign language, it would seem that other uses might be found. The shaping of phonological behavior of persons learning English as a foreign language, or of speakers of non-standard dialects of English might be attempted. In addition, the use of the equipment for teaching sound systems to deaf or retarded populations should be explored. A more concrete and immediate use would be with the language teacher. Since the teacher must act as the primary model in the classroom, it would seem vital to provide some means whereby the teacher could improve his own production of the sounds of the language he is teaching. It might also be an effective way to rid a teacher of poor articulation habits which may have been formed when he first studied the language. Perhaps it is in this area of teacher training that the device can contribute most to the field of education. These assumptions can only be tested by further experimentation with the device.

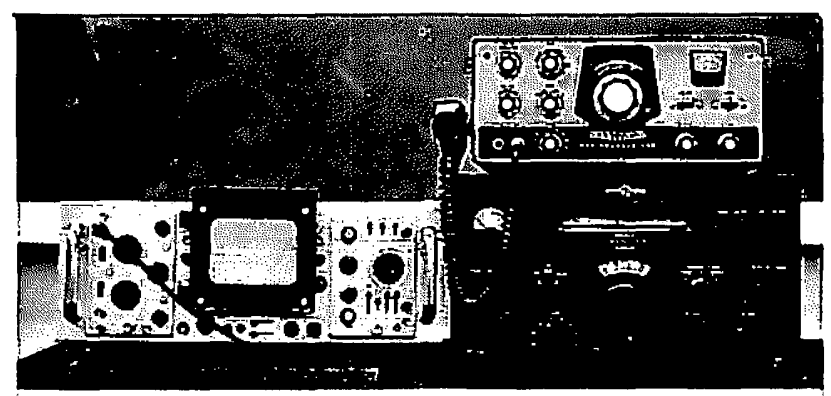

Figure 3. Photograph of the visual display device used in the study. 


\section{Verbal Modification}

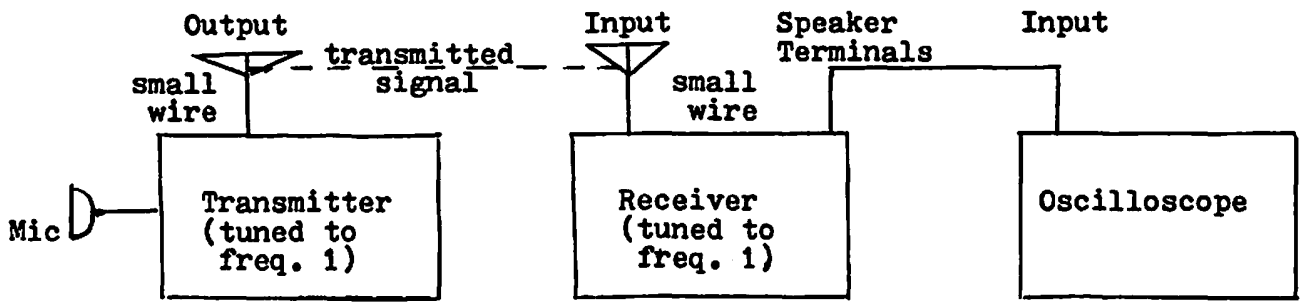

Figure 4. Equipment configuration of the visual display device.

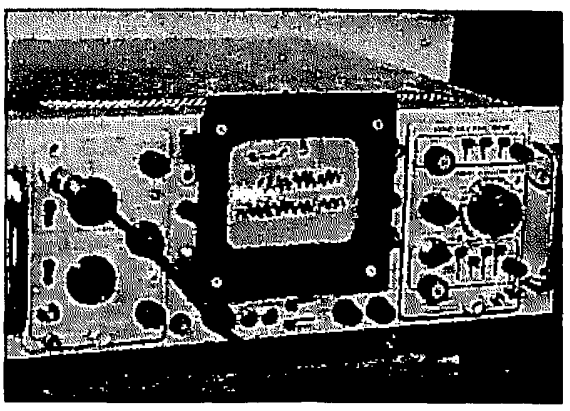

Figure 5. Photograph of the wave envelope of the German sound /oe/ and its production by female subject.

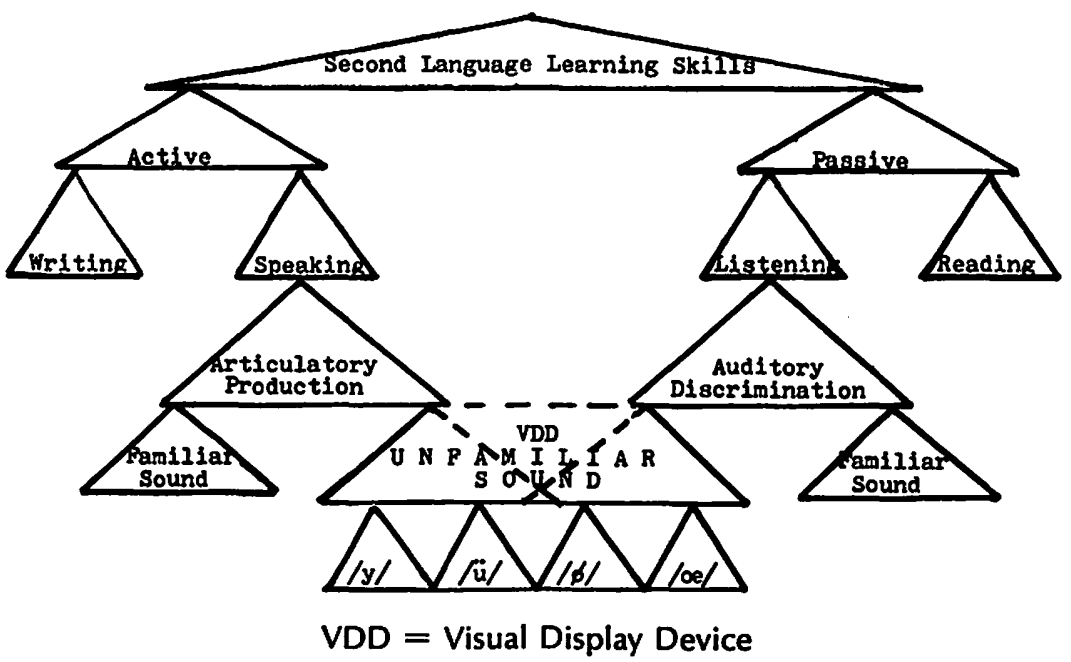

Figure 6. Analysis of the Experimental Task. 
Table 1

Reliability of Raters Based on the Intraclass Correlation Formula*

$\begin{array}{llllll}\text { Correlation } & .92 & .90 & .96 & .93 & .96\end{array}$

*See W. A. Mehrens \& R. L. Ebel (Eds.), Principles of Educational and Psychological Measurement, Chicago, 1067, pp. 118-119.

Table 2

Basic Statistics and t-test

Phoneme

Con $\quad \operatorname{Exp} t$ value

\begin{tabular}{|c|c|c|c|c|}
\hline & $\mathbf{N}$ & 30 & 31 & \\
\hline & $M$ & 3.417 & 2.690 & \multirow{4}{*}{3.974} \\
\hline \multirow[t]{3}{*}{$|y|$} & & & & \\
\hline & SD & 0.811 & 0.578 & \\
\hline & $M$ & 3.329 & 2.721 & \\
\hline \multirow[t]{3}{*}{$|u|$} & & & & \multirow[t]{3}{*}{3.541} \\
\hline & SD & 0.794 & 0.497 & \\
\hline & $M$ & 3.463 & 2.315 & \\
\hline \multirow{3}{*}{$10 /$} & & & & \multirow[t]{3}{*}{5.603} \\
\hline & SD & 1.023 & 0.453 & \\
\hline & $M$ & 3.886 & 2.878 & \\
\hline \multirow[t]{2}{*}{ loe/ } & & & & \multirow[t]{2}{*}{5.390} \\
\hline & SD & 0.857 & 0.552 & \\
\hline$M$ of & $M$ & 3.529 & 2.657 & \\
\hline Phonemes & SD & 0.753 & 0.327 & 5.801 \\
\hline
\end{tabular}




\section{References}

Campbell, D. T. \& Stanley, J. C. Experimental and Quasi-Experimental Designs for Research. Chicago: Rand McNally, 1963.

Carroll, J. B. Learning Theory for the Classroom Teacher. The ACTFL Review of Foreign Language Education, 1974, 6, 113-149.

Michaels, J: L. The Essential Components of Effective Instruction and Why Most College Teaching Is Not. In F. S. Keller \& E. Ribes-Inesta (Eds.) Behavior Modification, Applications to Education. New York: Academic Press, 1974.

Mueller, T. H. The Development of Curriculum Materials for Individualized FL Instruction. In H. B. Altman \& R. L. Politzer (Eds.) Individualizing Foreign Language Instruction: The Proceedings of the Stanford Conference. Rowley: Newbury House, 1971.

Teslaar, A. P. van. Learning New Sound Systems: Problems and Prospects. International Review of Applied Linguistics, 1965, 3 (2), 79-93.

Travers, R. M. W. Essentials of Learning (3rd. ed.) New York: Macmillan, 1967.

Valette, R. M. Modern Language Testing. New York: Harcourt Brace \& World, 1967. 